\title{
Conceptual study on grid-to-vehicle (G2V) wireless power transfer using single-phase matrix converter
}

\author{
Muhammad Qusyairi Iqbal Mohd Zamani, Rahimi Baharom, Dalina Johari \\ Faculty of Electrical Engineering, Universiti Teknologi MARA, Malaysia
}

\begin{tabular}{l}
\hline \hline Article Info \\
\hline Article history: \\
Received Sep 27, 2018 \\
Revised Feb 2, 2019 \\
Accepted Mar 24, 2019 \\
\hline
\end{tabular}

Keywords:

Electric Vehicle

Pulse Width Modulation

Single-Phase Matrix Converter

Wireless Power Transfer

\begin{abstract}
This paper presents the conceptual study on grid-to-electric vehicle $(\mathrm{G} 2 \mathrm{~V})$ wireless power transfer (WPT) using Single Phase Matrix Converter (SPMC). In this work, the SPMC is used as a direct AC to AC converter to convert the input supply voltage at $50 \mathrm{~Hz}$ frequency to the output of $20 \mathrm{kHz}$ to meet the WPT switching frequency operation of the transmitter and receiver coils. The high frequency $\mathrm{AC}$ voltage of the receiver coil is then rectified to a DC form by using SPMC. Through the proposed system, the battery of an electric car can be charged wirelessly, thus removing the annoying wires of the conventional electric vehicle charging system. The reduction in size of the charging system, power losses and optimum efficiency are among the advantages of the proposed system. MATLAB/Simulink (MLS) has been used to simulate the proposed model. Selected simulation result are presented to verify the proposed work.
\end{abstract}

Copyright (C) 2019 Institute of Advanced Engineering and Science. All rights reserved.

\section{Corresponding Author:}

Rahimi Baharom,

Faculty of Electrical Engineering,

Universiti Teknologi MARA,

40450 Shah Alam, Selangor, MALAYSIA.

Email: rahimi6579@salam.uitm.edu.my

\section{INTRODUCTION}

The WPT technology is a modern power transfer topology first introduced by Nikola Teslas more than 100 years ago [1-7] which refers to the transmitting of electrical power through air. The most popular approach to WPT employs an electromagnetic field (EMF) of some frequency as a means by which the electrical power was transmitted [1]. The WPT technology involves the process of electrical energy transmission from a power source to an electrical load across an air gap without using any wires or connectors $[8,9]$. The key elements of a WPT system are the transmitter and receiver coils.

An electric vehicle (EV) could be a vehicle fuelled by an electric engine instead of an internal combustion motor and the engine employs battery control [10,11]. Modern improvements in battery innovation, framework integration, optimal design, investigation and improvement by major vehicle producers have driven to the generation of electric vehicles on the roads of the city [12].

The WPT innovation, which can dispose of all the troublesome charging, is desirable for EV owners in comparison with conventional charging [13]. By exchanging vitality wirelessly to the EV, charging gets to be the most straightforward task. The drivers as it were got to stop their car and take off for a stationary WPT framework. For a dynamic WPT framework, which suggests that the EV can be driven; the EV can run without a stop until the end of time [14]. In expansion, the battery capacity of remote charging EV can be diminished to 20 percent or less than in conductive charging EV [15-25].

Figure 1 shows the typical concept of WPT for an EV system which consists of several stages to wirelessly transfer power from the supply to the load. It uses AC power as a source and change it to a DC form with power factor correction (PFC). The main parts of the WPT system could be summarized as follows:

Journal homepage: http://iaescore.com/journals/index.php/IJPEDS 
- The loosely coupled transmitting and receiving coils.

- The compensation network.

- The power electronics converters and control electronics.

The main difference between the proposed wireless charger and the conventional wireless charger system is that the two power electronics converters (AC to DC and DC to AC) is replaced by a SPMC circuit topology as shown in Figure 2. In this work, the SPMC is utilized to operate as a direct AC to AC converter to increase the operation frequency from $50 \mathrm{~Hz}$ to $20 \mathrm{kHz}$, thus removing the conventional two stage AC to DC and DC to AC converters. This enhanced circuit topology could lead to the reduction of the number of devices, and hence, reducing the total losses from the devices and improving the power density of the proposed wireless charging system.

\section{THE PROPOSED GRID TO VEHICLE WPT}

The proposed grid-to-vehicle $(\mathrm{G} 2 \mathrm{~V})$ wireless power transfer (WPT) battery charger system schematic circuit is shown in Figure 3. In the transmitter side, the SPMC1 is used to create a high-frequency output $\mathrm{AC}$ voltage. By employing the LC compensation network, a constant high frequency current can be maintained in the transmitter coil. Similar to the transmitter side, the parallel compensation is also adopted in the receiver side. With constant primary coil current and parallel secondary side compensation, the output acts like a current source. At a certain coupling, the current in the receiver coil is almost constant. By changing the duty ratio of SPMC2, the output power could be controlled.

The switching algorithm for the proposed G2V WPT battery charger system was developed based on the switching algorithm of AC to AC converter with safe-commutation technique. The SPMC1 is controlled to operate as a direct $\mathrm{AC}$ to $\mathrm{AC}$ converter with the switching frequency of $20 \mathrm{kHz}$, whilst, the $\mathrm{SPMC} 2$ is controlled to operate as an AC to DC converter.

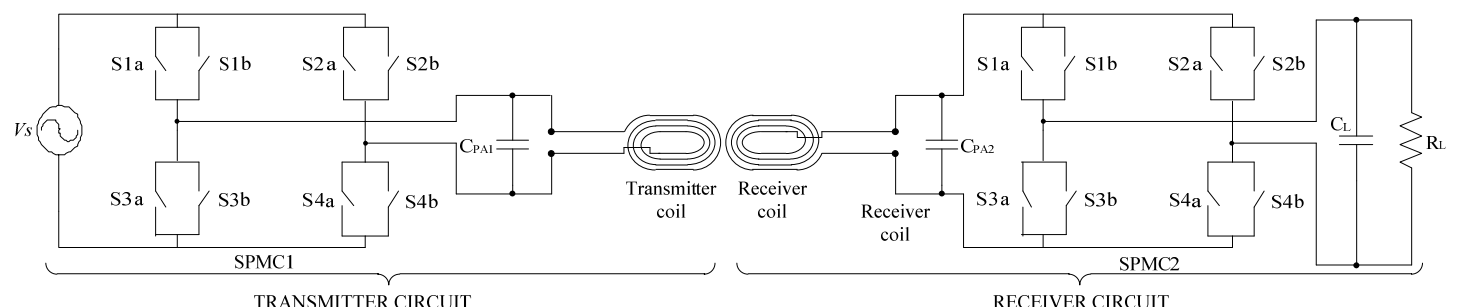

Figure 3. The proposed grid to vehicle (G2V) wireless power transfer (WPT)

\subsection{AC to AC converter operation}

The proposed switching strategies as tabulated in Table 1 are divided into four different modes called Modes 1, 2, 3 and 4 for different direction of output AC voltage. Four different switching states are developed to define complete possible operation during positive and negative cycle. The following set of rules is then defined;

- Mode 1: At this time, both switches S1a and S2b are turned 'ON' as shown in Figure 4(a). Then, S4a is turned 'ON' (after delay time) with the PWM switching pattern (providing overlap period). During this stage, current is flowing in the inductance (energized) through S4a and de-energized (commutation operation) through the S1a and S2b due to S4a 'OFF'.

- Mode 2: During this time, S4a is completely turned 'OFF' and the inductive load is de-energized due to overlap period of S3a and S4b as shown in Figure 4(b). Thus, S1b is turned 'ON' with the PWM switching pattern.

- Mode 3: Similar to Mode 1, during positive cycle operation, both switches S3a and S4b are turned 'ON' as shown in Figure 4(c). Then, S2a is turned 'ON' (after delay time) with the PWM switching pattern (providing overlap period).

- Mode 4: At this time, S2a is completely turned 'OFF' and the inductive load is de-energized due to overlap period of S1a and S2b as shown in Figure 4(d). Thus, S3b is turned 'ON' with the PWM switching pattern. A completed period is ended as shown in Figure 4(d).

Table 1. Switching algorithm for AC to AC converter at SPMC1 


\begin{tabular}{ccccc}
\hline Input cycle & Output cycle & States & PWM Switches & Commutation Switches \\
\hline \multirow{2}{*}{ Positive } & Positive & 1 & S4a & S1a and S2b \\
& Negative & 2 & S2a & S3a and S4b \\
& Positive & 3 & S3b & S1a and S2b \\
Negative & Negative & 4 & S1b & S3a and S4b \\
\hline
\end{tabular}

(a)

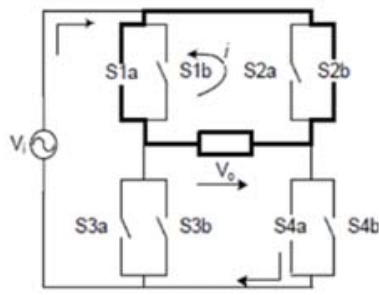

(c)

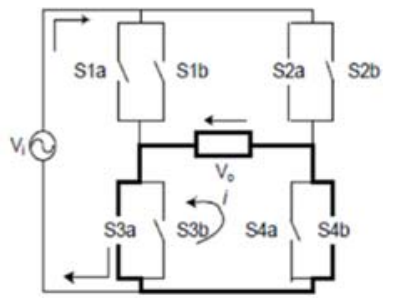

(b)

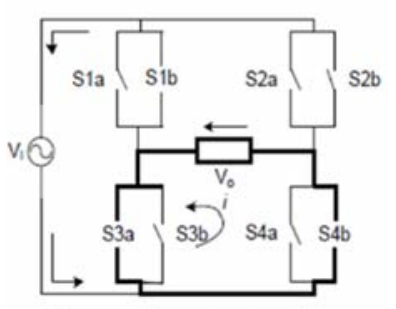

(d)

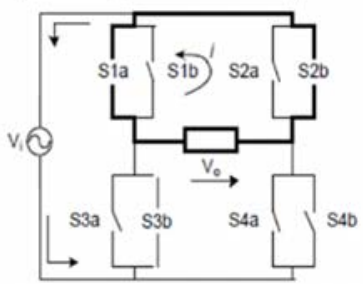

Figure 4. States of switching operations with safe-commutation techniques (a) Mode 1 (positive cycle), (b) Mode 2 (negative cycle), (c) Mode 3 (positive cycle), (d) Mode 4 (negative cycle)

\subsection{AC to DC converter operation}

By referring to Figure 5(a) for positive cycle operation, switch S1a is controlled by PWM signal, whilst switches S4a and S3b are always turned 'ON' prior to any switching functions. A similar arrangement is developed for the negative cycle implementation, where switch S3b is controlled by PWM signal, whilst switches S1a and S2b are always in the 'ON' state prior to any switching function as illustrated in Figure 5(b).

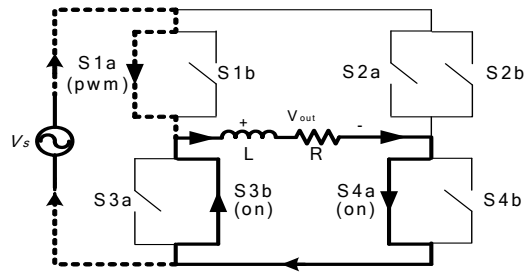

(a)

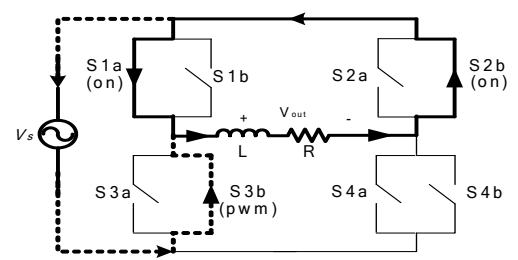

(b)

Figure 5. Controlled AC to DC (a) Positive cycle operation, (b) Negative cycle operation

\section{COMPUTER SIMULATION MODEL}

Figure 6(a) shows the top level main model of the proposed grid-to-vehicle (G2V) wireless power transfer (WPT) battery charger system. Table 3 shows the parameters used in the modelling of the proposed grid-to-vehicle (G2V) wireless power transfer (WPT) battery charger system. A subsystem is used in order to optimize the large model by breaking into a hierarchical set of smaller model for ease in implementation. Figures 6(b) to 6(f) are among the main subsystems represented by controlled unit model of AC to AC operation, AC to DC operation and PWM generator model.

The modelling of SPMC arrangement in MLS is shown in Figure 6(b), whilst Figure 6(c) shows the modelling of common emitter anti-parallel IGBT, with diode pair. The controller unit implements the operation of required switching state as presented in the previous section. It was divided into two operations either to control the AC to AC operation or AC to DC operation as shown in Figure 6(d).

Int. J. Pow. Elec. \& Dri. Syst. Vol. 10, No. 3, Sep 2019 : 1382 - 1388 
Table 2. Parameters of the G2V WPT battery charger system

\begin{tabular}{ll}
\hline \multicolumn{1}{c}{ Parameters } & \multicolumn{1}{c}{ Values } \\
\hline Input voltage, $V_{s}$ & $100 \mathrm{~V}, 50 \mathrm{~Hz}$ (Single phase) \\
Modulation Index & 0.5 \\
Loads & Resistor $=50 \Omega, \mathrm{L}=5 \mathrm{mH}$ \\
Switching frequency, $f_{s}$ & $20 \mathrm{kHz}$ \\
Output frequency & $20 \mathrm{kHz}$ (SPMC1) and $50 \mathrm{~Hz}$ (SPMC2) \\
\hline
\end{tabular}

(a)
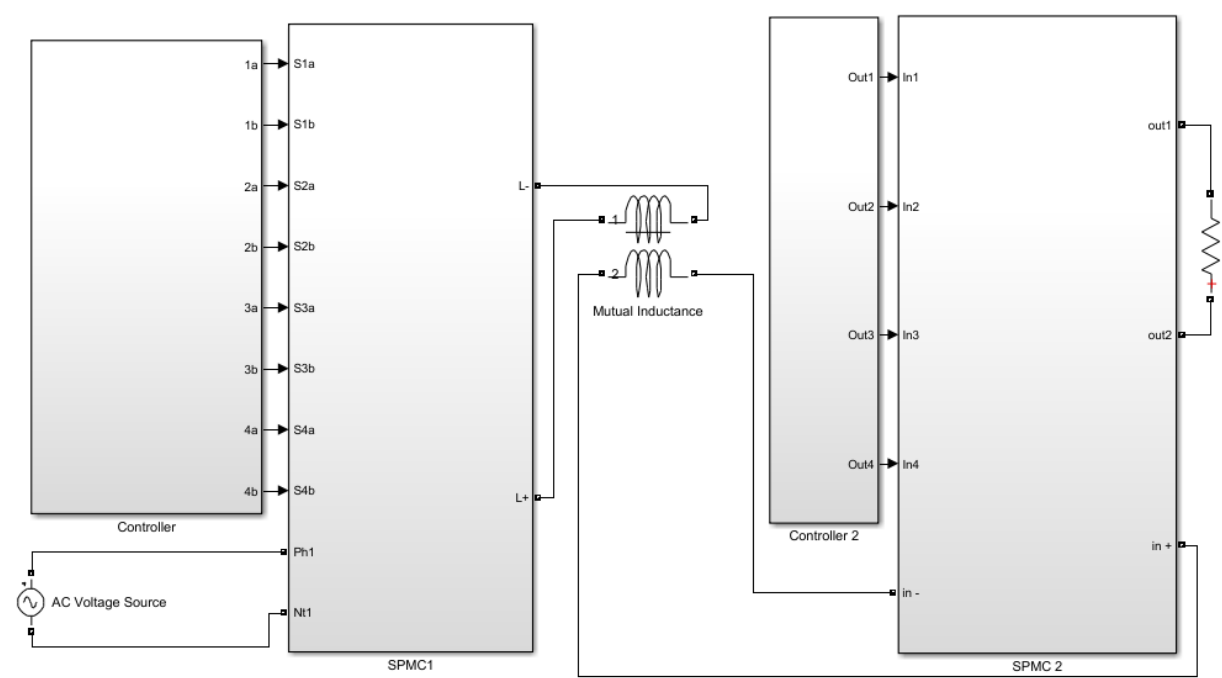

(b)

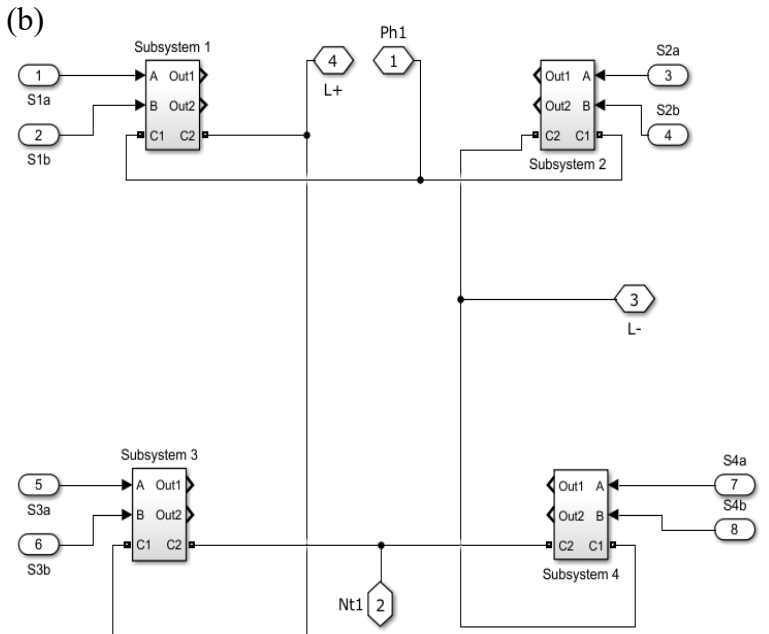

(c)

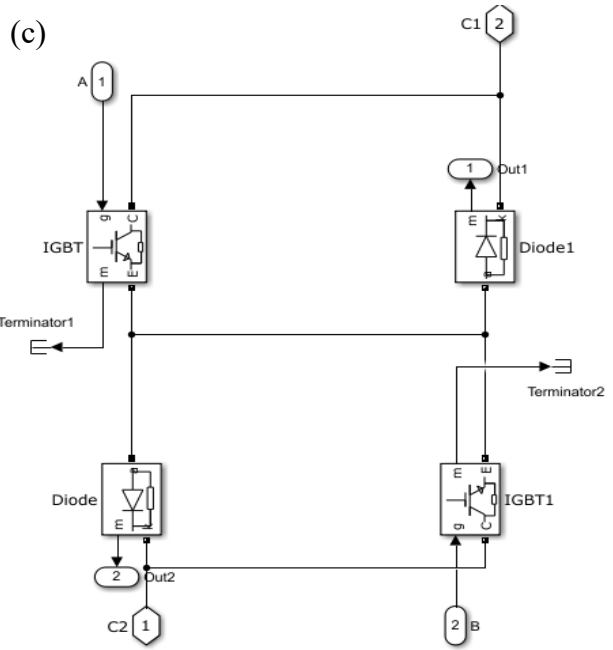

(d)
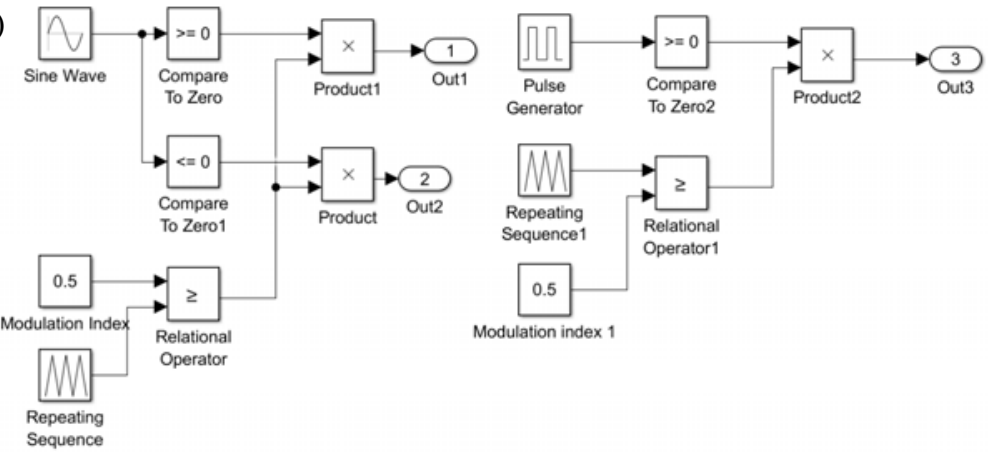

Modulation index 1

Figure 6. (a) Top level main model, (b) SPMC circuit model, (c) Bidirectional switch, and (d) PWM

\section{RESULTS AND DISCUSSION} generator

\footnotetext{
Conceptual study on grid-to-vehicle (G2V) wireless power ... (Muhammad Qusyairi Iqbal Mohd Zamani)
} 
This section presents the selected simulation results on the operation of the proposed grid-to-vehicle $(\mathrm{G} 2 \mathrm{~V})$ wireless power transfer (WPT) battery charger system. The function of the proposed operation includes; a) controlled AC to AC operation with safe commutation strategies, and b) wireless power transfer function, and c) AC to DC operation. Simulation studies were performed using MATLAB/Simulink to evaluate the operation of the proposed converter.

Figures 7 (a) and 7(b) show the simulation results of the supply voltage and current waveforms whilst Figures 8 (a) and 8 (b) show the results of output AC to AC converter that is fed to the transmitter coil of the WPT function.

A modulation index of 0.5 was used to illustrate sample results for a case of inductive load at a switching frequency of $20 \mathrm{kHz}$. A sinusoidal input voltage of $100 \mathrm{~V}$ (pk-pk) at $50 \mathrm{~Hz}$ and a resistive-inductive load of $50 \mathrm{ohm}$ and $5 \mathrm{mH}$ were initially used in this stage.

Figures 9 (a) and 9 (b) illustrate the results obtained from SPMC2 which is controlled to operate as an $\mathrm{AC}$ to DC converter with pure resistive load. It clearly shows that the output voltage and current waveforms are in DC forms. The introduction of capacitive load produces results as shown in Figure 10. It was observed that undesirable ripples as shown in Figure 9 (a), were successfully minimised.

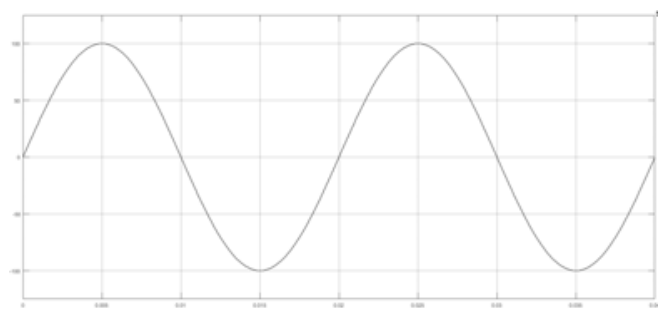

(a)

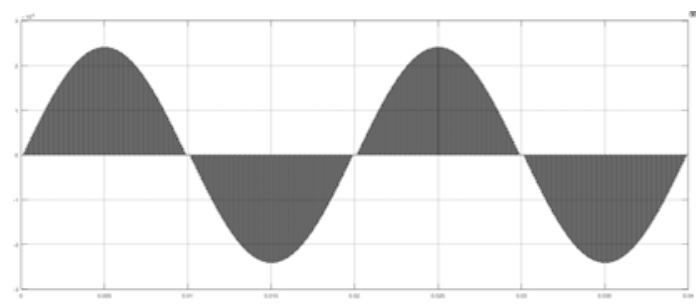

(b)

Figure 7. Waveform of (a) input voltage $\left(V_{\text {in }}\right)$; (b) input current $\left(I_{\text {in }}\right)$

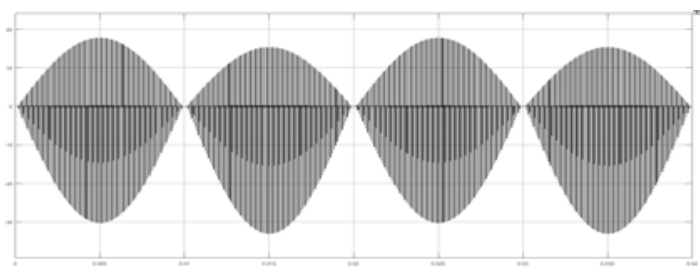

(a)

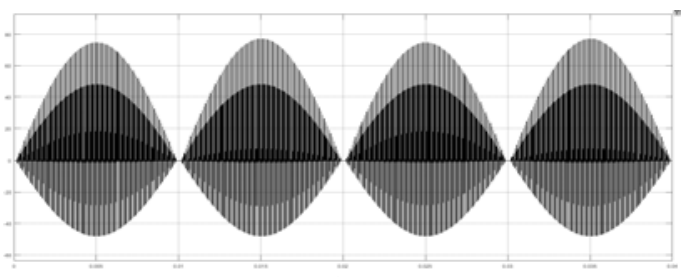

(b)

Figure 8. (a) Transmitter current waveform $\left(I_{p}\right)$, (b) transmitter voltage waveform.

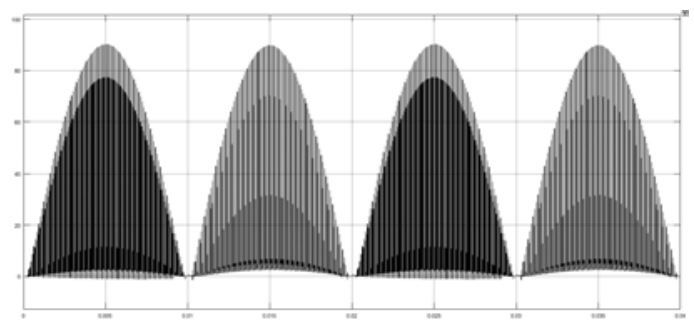

(a)

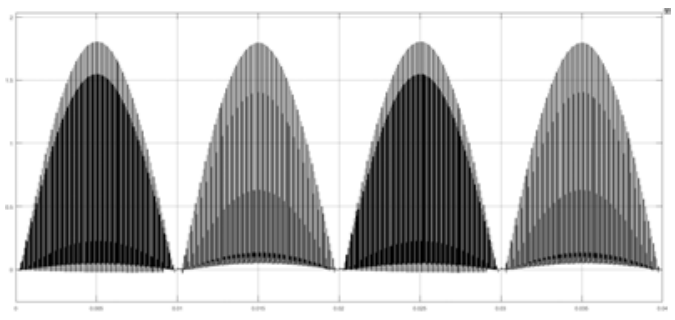

(b)

Figure 9. (a) Transmitter current waveform $\left(I_{p}\right)$, (b) transmitter voltage waveform. 


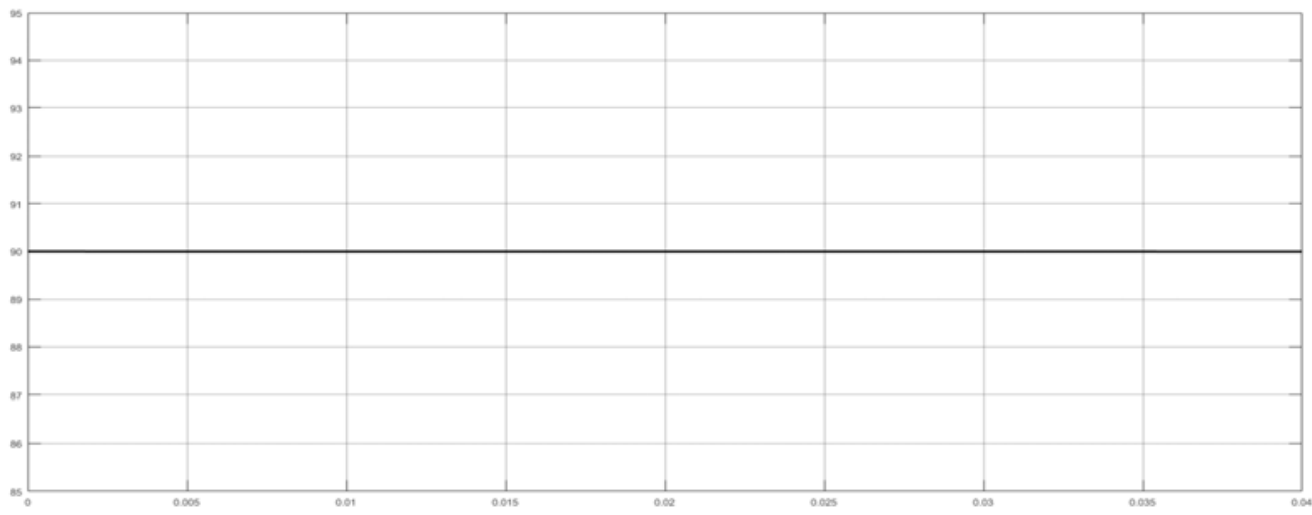

Figure 10. Output voltage $\left(V_{o}\right)$ waveform with RC load

\section{CONCLUSION}

In this paper, the design and operations of the conceptual study on grid-to-vehicle $(\mathrm{G} 2 \mathrm{~V})$ wireless power transfer using single phase matrix converter has been presented. Two types of operation were investigated; a) controlled AC to AC with safe commutation strategies, and b) AC to DC with capacitive load. In particular, the variation of modulation index by using pulse width modulation (PWM) technique to synthesize relevant output AC and DC waveforms has been considered. System simulations were performed using MATLAB/Simulink to ascertain basic power circuit behaviour and possible inaccuracies. It has been shown that the use of SPMC can be used to perform direct AC to AC converter, removing the complexity of the conventional AC-DC-AC converter, and thus, reducing the total losses of devices and improving the power density of the proposed wireless charging system.

\section{ACKNOWLEDGEMENTS}

Authors gratefully acknowledge the financial support from Institute of Research Management and Innovation (IRMI) Universiti Teknologi MARA Grant No: 600-IRMI/MyRA 5/3/BESTARI (029/2017).

\section{REFERENCES}

[1] D. M. Kesler, "Highly Resonant Wireless Power Transfer: Safe, Efficient, and over Distance," WiTricity Corporation, 2013.

[2] W. Zhong and S. Y. R. Hui, "Auxiliary Circuits for Power Flow Control in Multifrequency Wireless Power Transfer Systems with Multiple Receivers," IEEE Transactions on Power Electronics, vol. 30, no. 10, Oct 2015, pp. 5902-5910.

[3] L. P. Wheeler, "Tesla's Contribution to High Frequency," Electrical Engineering, vol. 62, no. 8, pp. 355-357, 1943.

[4] S. Y. Hui, "Planar Wireless Charging Technology for Portable Electronic Products and Qi," Proceedings of the IEEE, vol. 101, no. 6, pp. 1290-1301, June 2013.

[5] S. Y. R. Hui, W. Zhong, and C. K. Lee, "A Critical Review of Recent Progress in Mid-Range Wireless Power Transfer," IEEE Transactions on Power Electronics, vol. 29, no. 9, pp. 4500-4511, Sept 2014.

[6] M. Ettorre and A. Grbic, "A Transponder-Based, Nonradiative Wireless Power Transfer," IEEE Antennas and Wireless Propagation Letters, vol. 11, pp. 1150-1153, 2012.

[7] H. Hoang, S. Lee, Y. Kim, Y. Choi, and F. Bien, "An Adaptive Technique to Improve Wireless Power Transfer for Consumer Electronics," IEEE Transactions on Consumer Electronics, vol. 58, no. 2, pp. 327-332, May 2012.

[8] A. G. J. Taiber, "A Literature Review in Dynamic Wireless Power Transfer for Electric Vehicles: Technology and Infrastructure Integration Challenges," J. W. A. S. R. Trufin, Ed. Springer International Publishing, 2014.

[9] J. A. Russer and P. Russer, "Design considerations for a moving field inductive power transfer system," 2013 IEEE Wirel. Power Transf. WPT 2013, pp. 147-150, 2013.

[10] C. Maini, K. Gopal, and R. Prakash, "Making of an 'all reason' electric Vehicle," 2013 World Electr. Veh. Symp. Exhib. EVS 2014, pp. 1-4, 2014.

[11] B. Frieske, M. Kloetzke, and F. Mauser, "Trends in vehicle concept and key technology development for hybrid and battery electric vehicles," World Electr. Veh. J., vol. 6, no. 1, pp. 9-20, 2013.

[12] H. Weiss, T. Winkler, and H. Ziegerhofer, "Large Lithium-Ion Battery-Powered Electric Vehicles - From Idea to Reality,” 2018 ELEKTRO, pp. 1-5, 2018.

[13] L. Wang, J. Liang, G. Xu, K. Xu, and Z. Song, "A novel battery charger for plug-in hybrid electric vehicles,” 2012 IEEE Int. Conf. Inf. Autom. ICIA 2012, no. June, pp. 168-173, 2012.

Conceptual study on grid-to-vehicle (G2V) wireless power ... (Muhammad Qusyairi Iqbal Mohd Zamani) 
[14] J. Xiao, E. Cheng, N. Cheung, B. Zhang, and J. F. Pan, "Study of wireless charging lane for electric vehicles," 2016 Int. Symp. Electr. Eng. ISEE 2016, 2017.

[15] W. Jiang, S. Xu, N. Li, Z. Lin, and B. W. Williams, "Wireless power charger for light electric vehicles," Proc. Int. Conf. Power Electron. Drive Syst., vol. 2015-Augus, no. June, pp. 562-566, 2015.

[16] Z. Chen, W. Jing, X. Huang, L. Tan, C. Chen, and W. Wang, "A Promoted Design for Primary Coil in RoadwayPowered System,” IEEE Trans. Magn., vol. 51, no. 11, pp. 18-21, 2015.

[17] G. A. J. Elliott, G. A. Covic, D. Kacprzak, and J. T. Boys, "A new concept: Asymmetrical pick-ups for inductively coupled power transfer monorail systems," IEEE Trans. Magn., vol. 42, no. 10, pp. 3389-3391, 2006.

[18] G. A. Covic, J. T. Boys, M. L. G. Kissin, and H. G. Lu, "A three-phase inductive power transfer system for roadway-powered vehicles," IEEE Trans. Ind. Electron., vol. 54, no. 6, pp. 3370-3378, 2007.

[19] Meng Yao Li, Xiao Yuan Chen, Qin Huang, Guan Nan Bai, Jian Hui Liang, Li Na Wang, "Conceptual Design and Characteristic Analysis of a Rotary-Type Superconducting Wireless Power Transfer System Using ReBCO Primary at $50 \mathrm{~Hz}$ ", IEEE Transactions on Applied Superconductivity, Volume: 29, Issue: 2, Year: 2019.

[20] Zhengchao Yan, Baowei Song, Yiming Zhang, Kehan Zhang, Zhaoyong Mao, Yuli Hu, "A Rotation-Free Wireless Power Transfer System With Stable Output Power and Efficiency for Autonomous Underwater Vehicles", IEEE Transactions on Power Electronics, vol. 34, no. 5, pp. 4005-4008, 2019.

[21] Yongbin Jiang, Laili Wang, Yue Wang, Junwen Liu, Xiang Li, Gaidi Ning, "Analysis, Design, and Implementation of Accurate ZVS Angle Control for EV Battery Charging in Wireless High-Power Transfer", IEEE Transactions on Industrial Electronics, vol. 66, no. 5, pp. 4075-4085, 2019.

[22] Albert Ting Leung Lee, Weijian Jin, Siew-Chong Tan, S. Y. (Ron) Hui, "Buck-Boost Single-Inductor MultipleOutput High-Frequency Inverters for Medium-Power Wireless Power Transfer", IEEE Transactions on Power Electronics, vol. 34, no. 4, pp. 3457-3473, 2019.

[23] Zhang Hai Shi, Zhong Cai Qiu, Xiao Yuan Chen, Meng Yao Li, "Modeling and Experimental Verification of Bidirectional Wireless Power Transfer", IEEE Transactions on Applied Superconductivity, vol. 29, no. 2, 2019.

[24] Zhen Zhang, Hongliang Pang Apostolos Georgiadis, Carlo Cecati, "Wireless Power Transfer-An Overview", IEEE Transactions on Industrial Electronics, vol. 66, no. 2, pp. 1044-1058, 2019.

[25] Ke Jin, Weiyang Zhouk, "Wireless Laser Power Transmission: A Review of Recent Progress", IEEE Transactions on Power Electronics, vol. 34, no. 4, pp. 3842-3859, 2019.

Int. J. Pow. Elec. \& Dri. Syst. Vol. 10, No. 3, Sep 2019 : 1382 - 1388 